\title{
The use of non-destructive tests to estimate Self-compacting concrete compressive strength
}

\author{
Boukhelkhal Djamila $^{1}$, Guendouz Mohamed ${ }^{1}$ \\ ${ }^{1}$ LME Laboratory, University of Medea, Medea, Algeria
}

\begin{abstract}
Until now, there are few studies on the effect of mineral admixtures on correlation between compressive strength and ultrasonic pulse velocity for concrete. The aim of this work is to study the effect of mineral admixture available in Algeria such as limestone powder, granulated slag and natural pozzolana on the correlation between compressive strength and corresponding ultrasonic pulse velocity for self-compacting concrete (SCC). Compressive strength and ultrasonic pulse velocity (UPV) were determined for four different SCC (with and without mineral admixture) at the 3, 7, 28 and 90 day curing period. The results of this study showed that it is possible to develop a good correlation relationship between the compressive strength and the corresponding ultrasonic pulse velocity for all SCC studied in this research and all the relationships had exponential form. However, constants were different for each mineral admixture type; where, the best correlation was found in the case of SCC with granulated slag $\left(\mathrm{R}^{2}=0.85\right)$. Unlike the SCC with pozzolana, which have the lowest correlation coefficient $\left(R^{2}=0.69\right)$.
\end{abstract}

\section{Introduction}

Self-compacting concrete (SCC), was first developed in Japan in 1986. It is a special kind concrete that can flow through and fill the gaps of reinforcement and corners of molds without any need for vibration and compaction during the placing process $[1,2]$. This type of concrete demands a large amount of powder content compared to conventional vibrated concrete to produce a homogeneous and cohesive mix [3]. It was reported that SCC often contains powder in the order of 450-600 $\mathrm{kg} / \mathrm{m}^{3}$ of concrete [4]. One of its disadvantages is its high cost. An alternative for reducing the cost of SCC is the use of fine mineral additions which replace a part of the Portland cement [5-9].

Nondestructive testing of concrete is preferred due to its distinct advantage over conventional compression tests [10-12]. Moreover, ultrasonic pulse velocity (UPV) is one of the popular nondestructive techniques for evaluating the qualitative assessment of homogeneity in concrete. This method is typically based on the measurement of the propagation of velocity, which is closely related to strength of concrete [13]. However, the evaluation by nondestructive methods of the compressive strength of concrete is based generally on empirical relations between this property and nondestructive tests $[14,15]$.

In the construction industry, self-compacting concrete (SCC) has been increasingly used in ready-mix concrete and in the precast industry due to its technical advantages and to improve several aspects of construction $[16,17]$. The specific formulation of these concretes related to their implementation requirements could affect their mechanical behavior in the hardened state, compared to traditional vibrated concrete [18]. Many investigations by various researchers have shown empirical correlation models between the increase of UPV and the increase of the equivalent strength of concrete with age [19-23]. However, these models are only suitable for materials and environment similar to those which they are established.

There are few published studies on the effect of mineral admixtures on relationship correlation models for self-compacting concrete. So, the aim of this work was to study the effect of Algerian mineral admixture such as limestone powder, granulated slag and natural pozzolana on the correlation between compressive strength and corresponding ultrasonic pulse velocity in SCC.

\section{Materials and methods}

\subsection{Materials}

Ordinary Portland Cement (CEM I 42.5) with a fineness of $3370 \mathrm{~cm}^{2} / \mathrm{g}$ and a specific gravity of 3.15 $\mathrm{g} / \mathrm{cm}^{3}$ was used in this study. Three types of mineral admixtures were used with fineness comparable to that of cement: natural pozzolana (PZ); limestone powder (LP) and granulated slag (GS) their specific gravity are 2590 , 2544 and $2857 \mathrm{~kg} / \mathrm{m}^{3}$ respectively. The chemical 
compositions of Portland cement and mineral admixtures used in this study, are described in table 1 .

Table 1. Chemical analysis of cement and mineral admixtures used.

\begin{tabular}{|c|c|c|c|c|}
\hline $\begin{array}{c}\text { Chemical } \\
\text { Constituent (\%) }\end{array}$ & Cement & PZ & LP & GS \\
\hline $\mathrm{SiO}_{2}$ & 20.14 & 46.40 & 0.85 & 40.10 \\
\hline $\mathrm{CaO}$ & 63.47 & 9.85 & 53.08 & 42.20 \\
\hline $\mathrm{Al}_{2} \mathrm{O}_{3}$ & 3.71 & 17.50 & 0.93 & 6.00 \\
\hline $\mathrm{Fe}_{2} \mathrm{O}_{3}$ & 4.74 & 10.50 & 0.56 & 2.00 \\
\hline $\mathrm{MgO}$ & 2.12 & 3.45 & 0.23 & 4.70 \\
\hline $\mathrm{SO}_{3}$ & 2.67 & 0.40 & 0.60 & 0.15 \\
\hline $\mathrm{Ignition} \mathrm{los}$ & 1.72 & 4.31 & 42.55 & 0.05 \\
\hline
\end{tabular}

For the fineness modulus of sand used is about 2.50, we combined two sand: roller siliceous sand (S1) and crushed limestone sand (S2). The gravel used is a limestone crushed gravel with two granular classes $(3 / 8$ $\& 8 / 15)$. Figure 1 shows the particle size distribution curves of the aggregates used. The specific gravity of the coarse aggregates (G1, G2) and sand (S1, S2) were 2.66, $2.67,2.59$ and $2.63 \mathrm{~g} / \mathrm{cm}^{3}$ respectively; and their absorptions were $0.19,0.52,0.04$ and $0.38 \%$, respectively. To ensure the self-compacting concrete character, a chemical admixture superplasticizer type was used in this study.

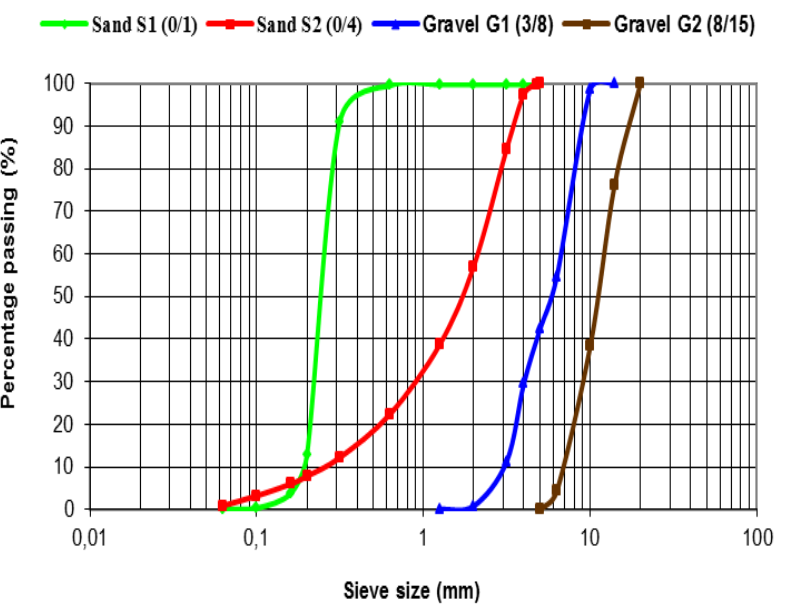

Fig. 1. Grading curves of fine and coarse aggregates used.

\subsection{Mix proportions}

To determine the quantities of materials: cement, aggregates, water and superplasticizer, we are based on the Japanese method proposed by Okamura [1], with some modifications are made to the sand content in mortar $(\mathrm{S} / \mathrm{M}=0.5)$, the water to cement ratio $(\mathrm{W} / \mathrm{C}=$ $0.42)$ and the superplasticizer to cement ratio $(\mathrm{Sp} / \mathrm{C}=$
1.6) to fit with the requirements of local materials and obtain good characteristics of fresh SCC [24].

Four SCC are prepared in this study with a total powder content of $470 \mathrm{~kg} / \mathrm{m}^{3}$ (Portland cement and mineral admixture), one without any admixture SCC-R and three mixes were prepared by replacing $15 \%$ of the cement with one of the three mineral admixtures utilized in this study separately namely: SCC-LP, SCC-GS and SCC-PZ.

\subsection{Test procedures}

The self compactability of fresh concrete was verified according to tests recommended by the AFGC [25]. Before casting, slump-flow, L-Box and sieve segregation resistance tests were attempted for determining the properties of SCC such as filling ability, passing ability and segregation resistance.

For each mixture, cube specimens $(10 \times 10 \times 10) \mathrm{cm}^{3}$ were used to determine the ultrasonic pulse velocity and compressive strength at $3,7,28$, and 90 days in accordance with NF EN 12504-4 [26] and NF EN 123903 [27], respectively. All specimens were demolded after $24 \mathrm{~h}$ and cured at $20^{\circ} \mathrm{C}$ and $95 \%$ relative humidity. The UPV test method employs the principle of measuring the travel velocity of ultrasonic pulses through a material medium. The pulse velocity equipment consists of an emitter (generating transducer) from which ultrasonic pulses are transmitted, a receiver (receiving transducer) where the pulses are received, and a device for indicating the time of travel from the transmitter to the receiver "Figure. 2.a". The compressive strength is determined by crushing specimen under an applied load until rupture "Figure 2b".
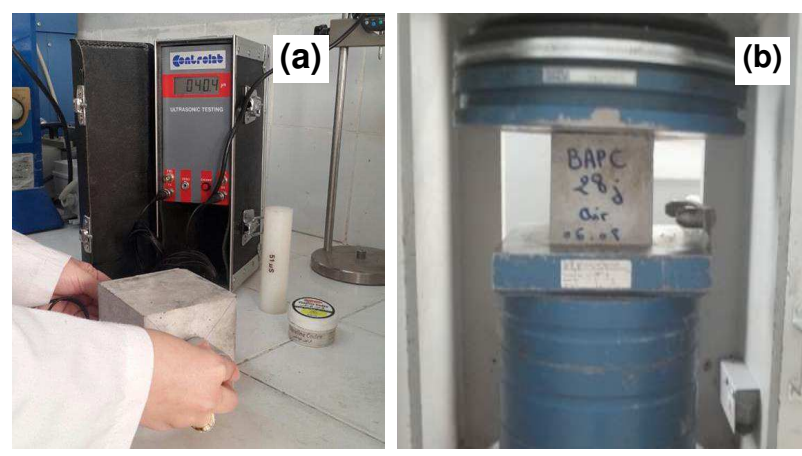

Fig. 2. Tests carried out in the hardened state (a/ ultrasonic pulse velocity test; b/ compressive strength test).

\section{Results and discussion}

\subsection{The effect of mineral admixtures on fresh properties of SCC}

The properties of fresh SCCs are presented in table 2 below. The results exposed in this table show that all mixtures, have verified the flow properties of SCC and meeting the requirements of the AFGC recommendations 
[25]. We can say also that the incorporation of limestone and blast furnace slag, remarkably improves all the fresh properties of SCC, compared to natural pozzolana which declined slightly their filling and passing capacity, but it increases the segregation resistance. The same results are shown by Uysal and Edamatsu [28, 29].

Table 2. Fresh properties of SCC mixes.

\begin{tabular}{|c|c|c|c|c|}
\hline Properties & SCC-R & SCC-LP & SCC-GS & SCC-PZ \\
\hline Slump flow $(\mathrm{mm})$ & 704 & 784 & 736 & 675 \\
\hline $\mathrm{H}_{2} / \mathrm{H}_{1}$ ratio $(\mathrm{L}-\mathrm{Box})$ & 0,87 & 0,97 & 0,91 & 0,81 \\
\hline Passing mortar S $(\%)$ & 4,05 & 6,25 & 5,48 & 2,37 \\
\hline
\end{tabular}

\subsection{The effect of mineral admixtures on compressive strength and UPV of SCC}

The compressive strength and UPV results of SCCs were determined on the $100 \mathrm{~mm}$ cubes for $3,7,28$, and 90 days. The results obtained for these tests are shown in figures 3 and 4 respectively. From these results, we can see as expected, that UPV progresses with age for all mixes and the increase has slowed after 28 days which is in the same line with the evolution of compressive strength versus time. It is remarked also that all produced SCCs were classified as good as all measured UPV values were greater than $3500 \mathrm{~m} / \mathrm{s}$.

Furthermore, lower ultrasonic pulse velocities were observed for SCC-LP compared to those of SCC-R at early and later age, indeed, the same behavior is observed for compressive strength. These results coincide with those found by Mucteba et al. [30] for SCC incorporating $20 \%$ of limestone powder. While almost the same UPV and compressive strengths were measured by SCC-R and SCC-PZ for all ages.

As regards the SCC-GS, comparable values to SCC-R were observed with a slight increase in ultrasonic pulse velocity and compressive strength are found after 28 days. In fact, SCC-GS gave the best ultrasonic pulse velocity at later ages compared to the other SCCs, which correlates with the values of compressive strength. The same result was confirmed by Mucteba et al. [30], Türkmen et al. [31] and Guneyisi et al. [32], which found an increase in ultrasonic pulse velocity in SCC with 10 and $20 \%$ granulated slag compared to the reference SCC.

\subsection{Correlation between compressive strength and UPV for SCC}

The different correlation models proposed between the compressive strength by crushing the specimens and the corresponding ultrasonic pulse velocity for different SCC mixes are shown in Figures 5. We can see from this figure, that all SCCs (with and without mineral admixtures) show a good correlation between the ultrasonic velocity and compressive strength (Correlation coefficients between 0,69 and 0,85). Moreover, all the relationships have the exponential form with different constant, which agree with other work for concrete with mineral admixtures [33-36]. We can see also that the best correlation was found for SCC-GS $\left(\mathrm{R}^{2}=0.85\right)$, while SCC-PZ present the lowest correlation compared to the other SCCs with a correlation coefficient of about 0.69 .

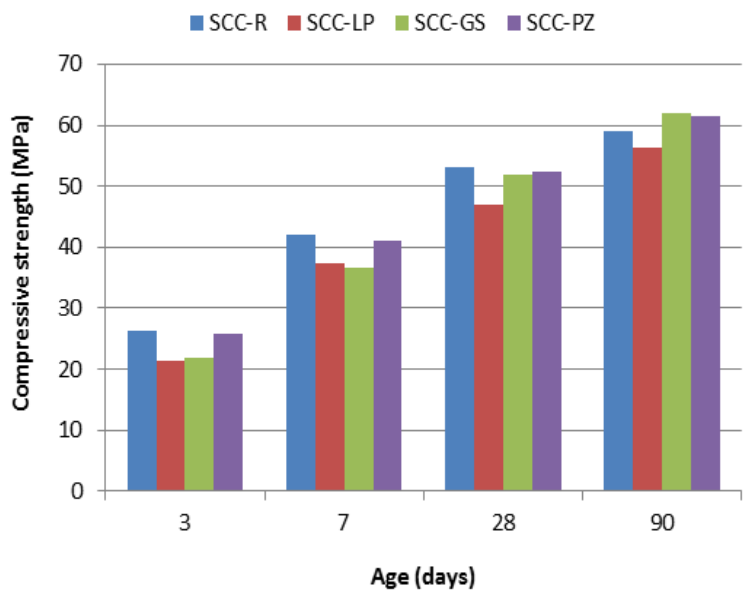

Fig. 3. Compressive strength results for SCC as function of mineral admixture type for different curing periods.

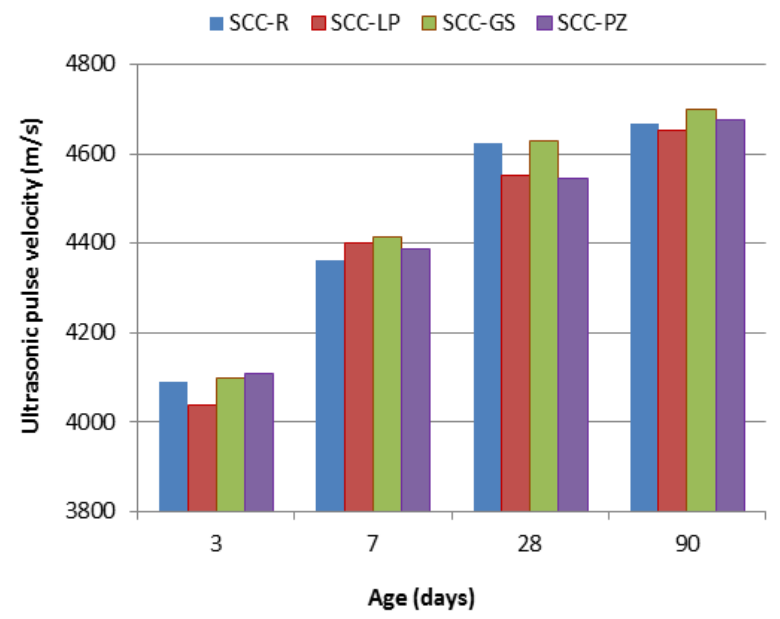

Fig. 4. UPV results for SCC as function of mineral admixture type for different curing periods.

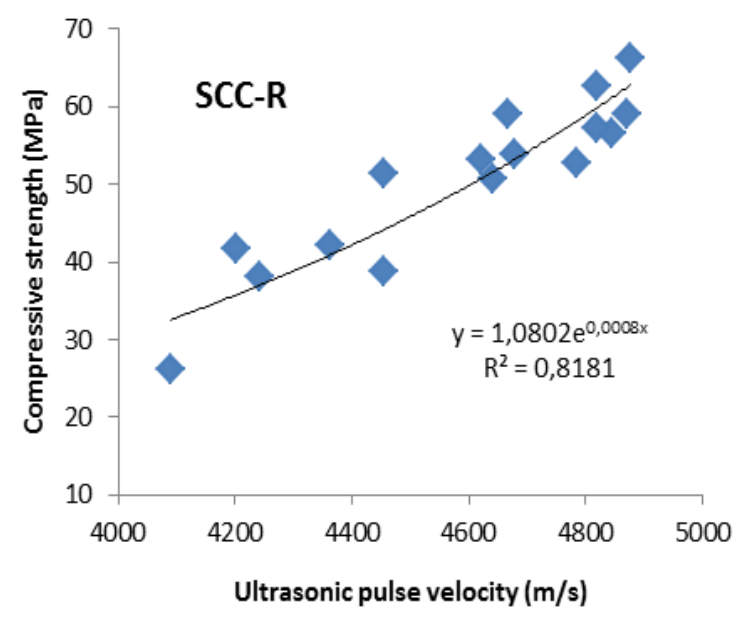

Fig. 5. Relationship between compressive strength and ultrasonic pulse velocity for reference SCC. 


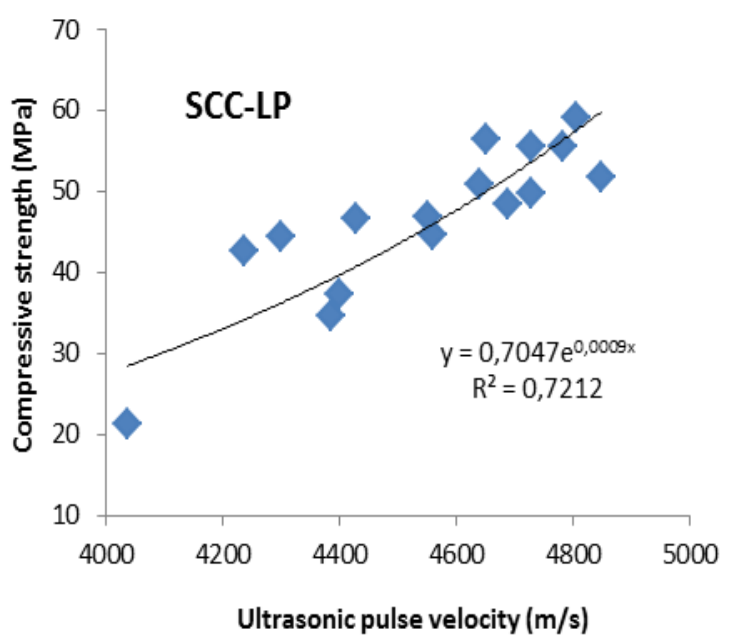

Fig. 6. Relationship between compressive strength and ultrasonic pulse velocity for SCC with limestone powder.

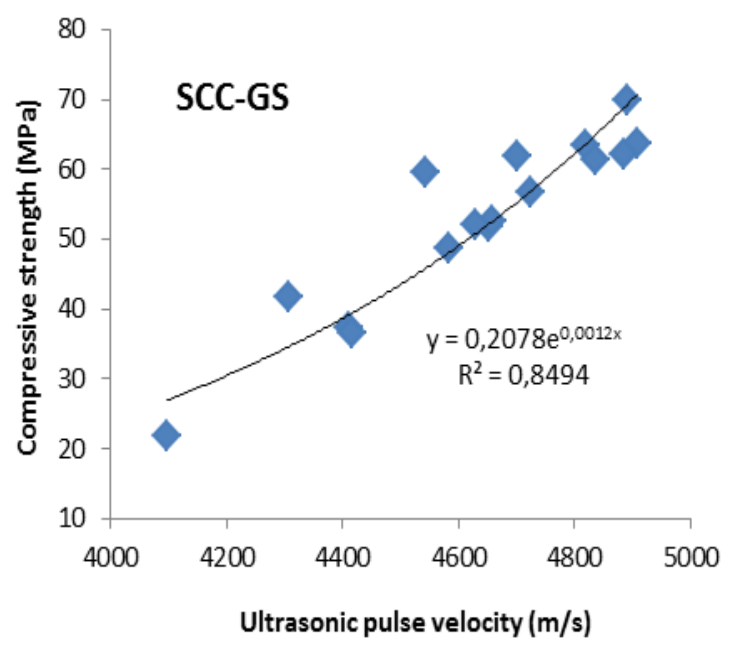

Fig. 7. Relationship between compressive strength and ultrasonic pulse velocity for SCC with granulated slag.

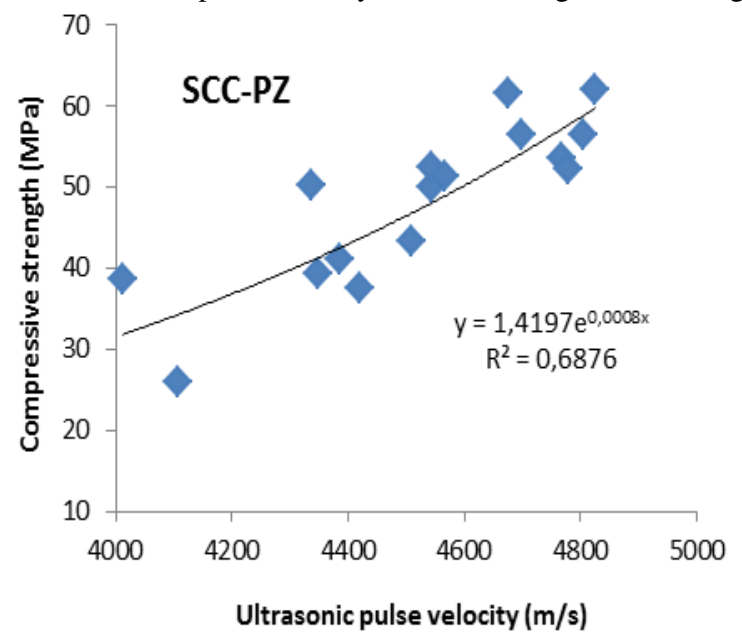

Fig.8. Relationship between compressive strength and ultrasonic pulse velocity for SCC with natural pozzolana.

\section{Conclusions}

Based on the results obtained through this study, the following conclusions have been drawn:

- It is possible to manufacture self-compacting concrete using Algerian mineral admixtures with acceptable fresh and hardened properties ;

- The use of granulated slag and limestone powder increased the flow properties of SCC, such as filling and passing ability. Unlike the natural pozzolana which has developed the least workable SCC, but it characterized by high resistance to segregation and consequently it leads to produce the more stable SCC ;

- In the context of compressive strength, all the SCCs could be considered to be satisfactory for structural applications. The UPV values increased with increasing curing period for all SCC, which is in the same line with compressive strength ;

- Introduction of LP induced a reduction in strengths and UPV of SCCs for all ages. The strength of SCC with slag and natural pozzolana exceeds that of controlled SCC after 28 days, with almost the same UPV, for all ages ;

- It is possible to develop a good correlation relationship between the compressive strength by crushing and the corresponding ultrasonic pulse velocity for all SCC studied in this research (with and without mineral admixtures) ;

- The correlation between UPV and compressive strength is also exponential for SCC containing mineral admixtures. However, constants were different for each type of mineral admixture in SCCs ;

- The best correlation was found in the case of SCCGS $\left(\mathrm{R}^{2}=0.85\right)$. Unlike the SCC-PZ, which have the lowest correlation coefficient $\left(\mathrm{R}^{2}=0.69\right)$;

- So we can say that the type of mineral addition, can affect the correlation between compressive strength and ultrasonic pulse velocity, and that the establishment of this correlation must be based on appropriate material to the study.

\section{References}

1. H. Okamura , M. Ouchi, J Adv Concr Technol, 1(1):5-15 (2003)

2. D. Bonen D,S.P. Shah S. P, Prog Struct Eng Mater, 7:14-26 (2005)

3. M.E. Barrak ,M. Mouret, A. Bascoul,J Cem Concr Compos. 31(1):12-21, (2009)

4. P. Nanthagopalan and M. Santhanam, Const. Build. Mater. 23(11):3443-9 (2009)

5. Bouzoubaa N and Lachemi M, "Self-compacting concrete incorporating high volumes of class $F$ fly ash: Preliminary results", Cement and Concrete Research, 31, 413-420 (2001) 
6. M. Guendouz, F. Debieb and E. H. Kadri, 33èmes roncontres de l'AUGC, ISABTP/UPPA, Anglet, 27 au 29 Mai 2015, Bayonne, France, (2015), p. 1-8.

7. P. Dinakar,K G. Babu and M. Santhanam, Cement \& Concrete Composites, 30, 880-886 (2008)

8. L. Coppola, T. Cerulli, and D. Salvioni, 11th International Conference on Fracture ICF11, Volume 3, pp. 2226-2241 (2005)

9. M. Guendouz, F. Debieb, O. Boukendakdji, E. H. Kadri, M. Bentchikou and H. Soualhi, J. Meter. and Env. Scien., 7(2), (2016), 227-232.

10. A.N. Bin Ibrahim, P. Bin Ismail and M. Forde, International Atomic Energy Agency, Vienna (2002)

11. J. Delacour and J.M. Geoffray, "Résultats et recommandations du projet national CALIBÉ : La maitrise de la qualité des bétons", Presses de l'école nationale des Ponts et Chaussées, Paris, France (2004)

12. D. Breysse, M. Larget, Z. Sbartai ,J. Lataste and J.P.Balayssac J. P., 7th International Symposium on Non-destructive Testing in Civil Engineering, Nantes, France, 8p (2009)

13. V.M. Malhotra and N.J. Carino, "Handbook on Nondestructive Testing of Concrete", 2nd Edition, .ASTM International, CRC Press (1991)

14. M. Nehdi,H.E Chabib, and A. Naggar, "Predicting Performance of Self-Compacting Concrete Mixtures Using Artificial Neural Networks", ACI Mat. J., vol. 98, no. 5, pp. 394-401 (2001)

15. D. Breysse and O. Abraham, "Méthodologie d'évaluation non destructive de l'état d'altération des ouvrages en béton", Presses de l'école nationale des Ponts et Chaussées, Paris, France (2005)

16. M. Yurugi, "Application of self-compacting concrete in Japan", Proceedings 23rd OWICS Conference, CI-Premier Ptc Ltd., Singapore, August 25- 26, pp. 29- 42 (1998)

17. O. Petersson , Cem. Concr. Res. Inst. 54 (2), 5 pp (1998)

18. Y. Klug and K. Holschemacher, "Comparison of the hardened properties of Self-Compacting and Normal Vibrated Concrete", $3^{\text {rd }}$ International Symposium on Self-Compacting Concrete, Reykjavik,Iceland, pp. 596-605 (2003)

19. J. Blitz and G. Simpson, "Ultrasonic Methods of Non-Destructive Testing", London: Chapman and Hall (1996)

20. H.Y. Qasrawi, Cement and Concrete Research, Vol.30, pp.739-746 (2000)

21. B. Hobbs and K.M. Tchoketch, Forensic Science International, Vol.167, pp.167-172 (2007)

22. A.B. Khodja A. B, "Corrélation entre essais non destructifs et essais destructifs du béton à faible résistance", Master theses, University of Hassiba Ben Bouali, Chlef, Algeria (2010)

23. DJ. Boukhelkhal, S. Kenai and F. Debieb, "Corrélation entre essais non destructifs et essais destructifs de la résistance du béton (Scléromètre \& Ultrason)", International Symposium on Nondestructive Testing in Civil Engineering DIAGNOBETON, Toulouse, France, 6p (2014)
24. O. Boukendakdji,E.H. Kadri ,S. Kenai , Cement \& Concrete Composites 34; 583-590 (2012)

25. AFGC, Association Française de Génie Civil, "Recommandations pour l'emploi des Bétons autoplaçant" (2008)

26. NF EN 12504-4 (2005), "Essais pour béton dans les structures. Partie 4 : Détermination de la vitesse de propagation du son", AFNOR.

27. NF EN 12390-3 (2003), "Essai pour béton durci. Partie 3 : Résistance à la compression des éprouvettes", AFNOR.

28. M. Uysal and K. Yilmaz, Cement and Concrete Composites J., Vol. 33,(2011),pp.771-6.

29. Y. Edamatsu, T. Sugamata and M. Ouchi , "A mixdesign method for self-compacting concrete based on mortar flow and Funnel tests". In: Proceedings of $3^{\text {rd }}$ international symposium on self- compacting concrete, Reykjavik, Iceland, (2003) p. 345-55.

30. U. Mucteba, S. Mansur, Construction and Building Materials J., Vol.25, (2011),pp. 4112-4120.

31. I. Türkmen,A. Aliöz and A.Cüneyt, , Scientific Research and Essays J., Vol. 5(15), (2010),pp. 2055 2064.

32. E. Guneyisi and M. Gesoglu, Materials and Structures J., Vol. 41, (2008), pp. 479-493.

33. K. Tharmaratnam and B.S. Tan, Cement and Concrete Res. 20: (1990). 335-345.

34. R. Demirboğa and M.R. Türkmen Karakoç, (2004), Cement Concrete Res. 34: 2329-2336.

35. Z.C. Ulucan, K. Turk and M. Karatas, Russian Journal of Nondestructive Testing, Vol. 44, $\mathrm{N}^{\circ} 5$, ,(2008) pp. 367-74.

36. C.U. Zulfu, T. Kazim and K. Mehmet, , Russ. J. Nondestructive Test 44, pp. 367-374, (2008). 